\title{
A three-model comparison of the relationship between quality, satisfaction and loyalty: an empirical study of the Chinese healthcare system
}

Ping Lei ${ }^{1 *}$ and Alain Jolibert ${ }^{2}$

\begin{abstract}
Background: Previous research has addressed the relationship between customer satisfaction, perceived quality and customer loyalty intentions in consumer markets. In this study, we test and compare three theoretical models of the quality-satisfaction-loyalty relationship in the Chinese healthcare system.

Methods: This research focuses on hospital patients as participants in the process of healthcare procurement. Empirical data were obtained from six Chinese public hospitals in Shanghai. A total of 630 questionnaires were collected in two studies. Study 1 tested the research instruments, and Study 2 tested the three models. Confirmatory factor analysis was used to assess the scales' construct validity by testing convergent and discriminant validity. A structural equation model (SEM) specified the distinctions between each construct. A comparison of the three theoretical models was conducted via AMOS analysis.

Results: The results of the SEM demonstrate that quality and satisfaction are distinct concepts and that the first model (satisfaction mediates quality and loyalty) is the most appropriate one in the context of the Chinese healthcare environment.

Conclusions: In this study, we test and compare three theoretical models of the quality-satisfaction-loyalty relationship in the Chinese healthcare system. Findings show that perceived quality improvement does not lead directly to customer loyalty. The strategy of using quality improvement to maintain patient loyalty depends on the level of patient satisfaction. This implies that the measurement of patient experiences should include topics of importance for patients' satisfaction with health care services.
\end{abstract}

Keywords: Perceived quality, Patient satisfaction, Patient loyalty, Models comparison, Health service

\section{Background}

China's healthcare system is on the brink of major reform, stimulated by a multitude of forces that are driving this change [1]. Since 2002, the Chinese government has primarily allocated its healthcare funding to graduates of medical schools and public hospitals in major cities in an effort to improve the quality of patient care. The strong government commitment to improving health services and patient satisfaction was further emphasized after the 2003 SARS outbreak, when in 2005 the "Year of Hospital Management Reform" was declared, with the

\footnotetext{
* Correspondence: p.lei@esc-chambery.fr

'Groupe Ecole Supérieure de Commerce Chambéry Savoie, France, 12 Avenue du Lac d'Annecy, Le Bourget du Lac Cedex, Chambéry, Savoie 73381, France

Full list of author information is available at the end of the article
}

key theme of "the patient comes first, improve the quality of service." In this way, the Chinese government articulated its pledge to the healthcare sector and emphasized the need for public and private sector cooperation [1]. These actions demonstrate the government's commitment to developing hospital management and organization in a patient-centered manner to increase patient satisfaction.

Simultaneous with the government's new commitment, Chinese patients are becoming more knowledgeable and active in "managing" their healthcare experiences. In major cities, there are increasing numbers of individuals who are taking "responsibility" for their healthcare. There is increasing demand for improved hospital-based services, patients are becoming better informed, and, in turn, 
more demanding about the type and quality of health services they expect to receive. The government has, in fact, already encouraged the "voice of the consumer" by soliciting patient feedback in evaluating hospitals to help improve the level of patient care.

Because of these circumstances, Chinese hospitals are now operating in a new, complex and uncertain environment. The current transformation from a Communist system to a competitive healthcare market is obliging hospital providers to deal with decreased funding and increased competition. Facing this situation, providers must learn to cost-effectively satisfy the needs and desires of their patients. As a result, providers and policymakers are urgently seeking a clear understanding of the quality, satisfaction and loyalty intention relationship in the Chinese healthcare market.

Many researchers have studied patient satisfaction in Western healthcare services [2-7], and there are some that have studied patient satisfaction in Hong Kong and Taiwan [8-10]. However, to date no research has focused on mainland China's healthcare market.

Over the past 30 years, a large number of consumer behavior studies have explored the links between quality, consumer satisfaction and loyalty in Western cultures, yet no consensus has been reached. Three theoretical models can, however, be found in the literature [11].

Faced with three contradictory theoretical models, it is challenging to determine which model is most appropriate to utilize in studying healthcare services in mainland China. The purpose of this study is to analyze the relationships between perceived quality, patient satisfaction and loyalty intentions in mainland China's healthcare system.

The empirical data for this study was collected in Shanghai (eastern China), where patients have substantial freedom to choose their medical providers.

\section{Theoretical background and research hypotheses}

Our conceptual models focus on the relationships between perceived quality, loyalty and satisfaction. Three models can be built from the existing literature (Table 1).

\section{Table 1 Hypotheses and supporting literature}

\begin{tabular}{|c|c|c|}
\hline & Hypotheses & Supporting literature \\
\hline H1: & $\begin{array}{l}\text { Customer satisfaction mediates perceived } \\
\text { quality and loyalty intention relationship }\end{array}$ & {$[5,6,9,13-22,27,53]$} \\
\hline H2: & $\begin{array}{l}\text { Perceived quality and customer satisfaction } \\
\text { influence customer loyalty intention with } \\
\text { equal weight }\end{array}$ & {$[11,13,18,29-32]$} \\
\hline H3: & $\begin{array}{l}\text { Perceived service quality mediates the } \\
\text { relationship between customer satisfaction } \\
\text { and customer loyalty intention }\end{array}$ & {$[11,15-17,33,34]$} \\
\hline
\end{tabular}

\section{Customer satisfaction mediates the quality-loyalty relationship}

Perceived quality is considered the antecedent of satisfaction and customer loyalty. Therefore, customer loyalty stems primarily from perceived quality. Perceived quality directly influences customer loyalty and customer satisfaction. Therefore, customer satisfaction partially mediates the quality-loyalty relationship [12-14].

Several studies support this model [15-22]. Based on this approach, the process of achieving satisfaction has been described as follows. Before buying, consumers form expectations of a specific product or service. Then, consumption induces a perceived quality level that is influenced by the difference between actual quality perceptions and the expectations of quality $[23,24]$. If perceived quality is confirmed, then customers are satisfied. Intensity of customer loyalty is then influenced by the degree of customer satisfaction, and perceived quality is considered to influence customer loyalty.

However, the observed relationship between perceived quality and customer loyalty relies on customer satisfaction, as customer satisfaction is a mediator variable in the quality-loyalty relationship [25]. Perceived quality can be a root cause of customer loyalty. Customer satisfaction can easily be added as a third variable to the quality-loyalty relationship, wherein perceived quality causes satisfaction, and customer satisfaction causes loyalty intention. Therefore, in the mediation model, when customer satisfaction is introduced into the perceived quality-loyalty relationship, the path coefficient of this relationship drops to a non-significant level or disappears [26].

In healthcare services, several studies have used perceived quality to assess patient satisfaction $[5,8,9,13,14,27]$. They indicate that patient satisfaction is the key indicator in determining the relationship between perceived healthcare quality and patient loyalty intention $[8,28]$. This approach considers customer satisfaction as a mediator between perceived quality and loyalty intention as shown in Figure 1.

\section{Perceived quality and customer satisfaction are one and the same}

In this model, perceived quality and customer satisfaction constructs are placed at the same level [11]. Based on this approach, these two constructs have an equivalent effect on customer loyalty intention [29].

From a nomological point of view, the two concepts are separable theoretical constructs if they occupy unique positions in a nomological network as determined by unique sets of antecedent causes, consequential effects or both [30]. Conversely, if two concepts share the same theoretical antecedents and consequences, then they are "structurally equivalent" or 


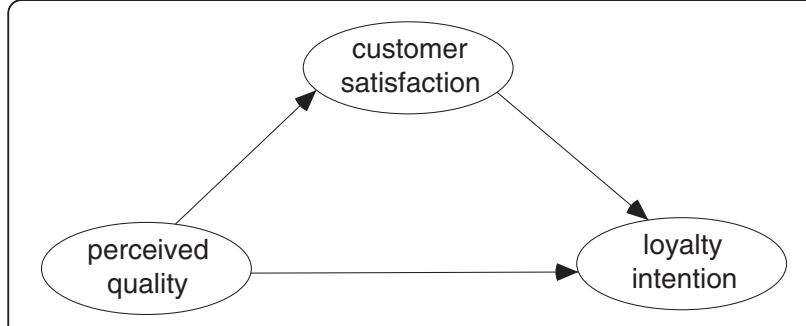

Figure 1 Quality-satisfaction-loyalty model.

logically isomorphic. In this case, the standard definitions of quality and satisfaction share the same antecedents (expectation and perception of the purchase experience) and consequences (both lead to loyalty intention). The positions of quality and satisfaction in this nomological network are not unique, but are structurally interchangeable [29].

Several healthcare service studies have used perceived quality as a patient satisfaction measure [13,18,31,32]. They suggest that meeting patient expectations is essential to maintaining a good patient-provider relationship [32]. However, to meet a patient's expectations, healthcare providers must know their patients and understand their expectations. Because expectation has been defined as customer desire, service expectations do not represent what service providers offer in reality, but rather what they should offer. That is, patient satisfaction is more likely to be determined by how well provider performance fulfills innate needs, wants or desires, rather than how performance compares with presumed predictions [31]. This approach considers that perceived quality and customer satisfaction influence customer loyalty intention with equal weight, as represented in Figure 2.

\section{Perceived quality mediates the relationship between satisfaction and loyalty}

According to this approach, customer satisfaction influences customer loyalty intention directly, but also influences perceived quality $[11,33]$. Therefore, perceived quality is a mediator between customer satisfaction and customer loyalty.

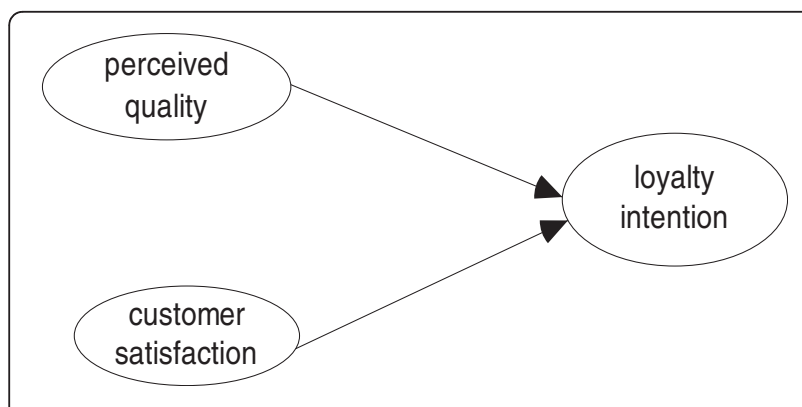

Figure 2 Quality and satisfaction as "one and the same" model.
Although there is widespread agreement that customer satisfaction is induced by performance quality, customer satisfaction may largely influence perceived quality as well. For instance, a customer might be satisfied with a particular service, but they do not think the service is of high quality. This confirms that quality evaluation is influenced by customer satisfaction, and customer satisfaction can be modeled as an antecedent of perceived quality. Using this interpretation, perceived quality is built mainly on previous experiences of (dis) satisfaction related to discrete transactional episodes [15-17]. Therefore, satisfaction is an emotional reaction that results from an intrapersonal comparison of customer expectation with the evaluation of a single product or service encounter [11]. This emotional state of satisfaction leads to an overall attitude regarding perceived quality $[33,34]$. In this approach, multiple satisfaction evaluations contribute to an overall perceived quality evaluation, leading to the conclusion that customer satisfaction is an antecedent of perceived quality. Perceived quality thus mediates the satisfaction-loyalty relationship [11].

There are studies documenting perceived quality as mediating customer satisfaction and customer loyalty in some service industries [11,33]. However, a broader review of the literature reveals a limited number of studies addressing perceived quality as mediating the satisfaction-loyalty relationship in the healthcare sector. Therefore, this research studies the relationship of quality as a mediator between satisfaction and loyalty in the Chinese healthcare sector. This approach considers perceived service quality as a mediator of the relationship between customer satisfaction and customer loyalty intention as shown in Figure 3.

\section{Methods}

\section{Data collection}

This study used inpatients as research participants to assess the relationship between perceived quality, patient satisfaction and patient loyalty intention constructs.

\section{Hospital sample}

The six hospitals chosen for the studies were located in Shanghai, China. Based on the classification of Shanghai hospitals, we selected among the city's 33 tertiary public

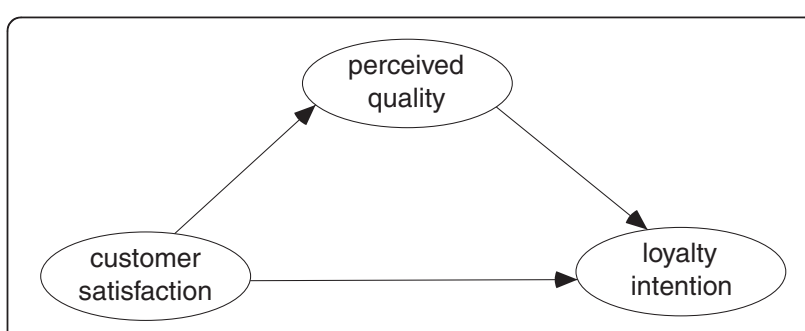

Figure 3 Satisfaction-quality-loyalty model. 
hospitals. Tertiary hospitals are general hospitals located in the city, with a bed capacity exceeding 500. These hospitals treat local residents and patients with difficult and complex diseases from all over the country [35]. Among the 33 tertiary hospitals, 6 were selected for our study (Table 2). They ranged from the largest urban teaching hospitals (Fudan University Zhongshan, Huashan, Jinshan and Shanghai No. 5 People's Hospital) to mid-sized municipal hospitals (Shanghai Oriental Hospital and Shanghai Minhang District Hospital). Among the six hospitals, two were located in urban areas, two in suburban areas and two in rural settings. The six hospitals are the largest from among the three categories of hospitals. Therefore, the selected hospitals represent the Chinese inpatient population fairly well.

\section{Inpatient sample}

Data were collected by four non-medical students. These students were trained to collect data on hospital patients who underwent surgery in the 30 days prior to administration of the questionnaire. Data were collected from the inpatient healthcare services department in the six public hospitals. A questionnaire was given to a systematic probability sample of individuals in two phases.

Of the 6,200 licensed beds in the 6 hospitals (Table 2), a total of 800 inpatients were selected according to a systematic sample procedure using odd numbered beds, from a bed number list established at each hospital. Questionnaires were distributed to participants who underwent surgery in the 6 hospitals in the 30 days prior to the administration of the questionnaire. A quota sampling based on the number of beds per hospital was used to obtain the number of inpatients to be questioned per hospital. Table 2 provides the number of questionnaires per hospital. Of the 800 questionnaires, 200 were distributed in the first phase, and 600 were distributed in the second phase.

With a response rate of 78 percent, 646 surveys were collected over the two phases (150 questionnaires were collected in the first phase and 496 were collected in the second phase). Empty beds and patients who were not

Table 2 Sample of six public hospitals, Shanghai, 2009 and number of questionnaires

\begin{tabular}{lll}
\hline Hospital name & $\begin{array}{l}\text { Number of } \\
\text { beds }\end{array}$ & $\begin{array}{l}\text { Number of } \\
\text { questionnaires }\end{array}$ \\
\hline Shanghai Zhongshan Hospital & 1,700 & 150 \\
Shanghai Huashan Hospital & 1,326 & 130 \\
Shanghai Dongfang Hospital & 1,000 & 100 \\
Shanghai Jinshan Hospital & 600 & 60 \\
Shanghai Minhang District & 800 & 80 \\
Centre Hospital & & \\
Shanghai No.5 People's Hospital & 800 & 80 \\
\hline
\end{tabular}

in a position to answer constituted non-responses. Sixteen surveys were discarded because of missing data. The final sample included 630 responses (150 in the first phase and 480 in the second phase) available for statistical analysis.

The sample was made up as follows: 51 percent males and 49 percent females (aged between 20 and 65 years); 48 percent had less than a high school level education, 27 percent had a high school education, 13 percent were university graduates and 11 percent were post-graduates; 25 percent had a monthly income below $\$ 250,57$ percent between $\$ 250-\$ 500,8$ percent between $\$ 500-\$ 750$ and 10 percent had a monthly income of more than $\$ 750$. We did not consider patients under 20 years of age because of the risk of influence by staff and researchers [4] or those aged over 65 because Medicare Insurance issues related to retirement might interfere with respondent judgment [36].

Patients' personal information was obtained from the hospital administration. To protect patient privacy and encourage the free expression of patient opinions, we did not include information such as patient name, address or diagnosis in the study. An explanatory note describing the study to respondents was placed at the beginning of the questionnaire. All participants were asked to confirm their agreement to participate before the actual survey was administered and all of them confirmed.

\section{Measures}

The patient-perceived quality scale was developed based on the SERVQUAL instrument as recommended by Parasuraman, Zeithaml and Berry [37]. Based on its original form, SERVQUAL contains 22 pairs of reflective 7point Likert scales $(1=$ strongly disagree, $7=$ strongly agree). One half of these items measure the patients' expected level of health service quality. The other half measures the perceived level of health service quality provided by hospitals. Perceived quality is measured using disconfirmation scores based on patient healthcare service quality perceptions minus service quality expectations (P-E).

Based on Cho et al. [8] and Fitzpatrick [38] patient satisfaction was measured using an overall measure of satisfaction rating, because it reflects the personal preferences of the patient, patient expectations and the reality of the care received [3]. Furthermore, it suppresses the validity and reliability bias observed when using the determinant of satisfaction [39]. Three reflective items were used: 1) How would you rate the overall quality of service provided by your hospital? 2) Thinking about the hospital overall, please rate the value you feel you get for your money. 3) Overall, how satisfied are you with your hospital? All three used 10-point semantic differential scales ranging 
from 1 to $10(1=$ very satisfied, $10=$ very dissatisfied $)$. Despite the existing controversy regarding their respective properties [40], 10-point scales were preferred to the usual 5-point scales because in health care satisfaction studies, they show higher validity and explanatory power than 5-point scales and the same non-response rate [41]. We used an inverted score scale to avoid response style bias, such as consistently responding yes. This choice is quite common in investigations where one can justifiably fear a "positive" bias, as is the case in China (and other cultures where individuals tend not to say no directly). According to Baumgartner and Steenkamp [42], and Peter and Churchill [43], studies show that an inverted score scale does not lower scale reliability.

Word of mouth (WOM) is used as a reflective indicator of patient loyalty. In medical services, loyalty through repeat patronization is not pertinent, whereas patient WOM [44] has an important impact on responses for several reasons [5]. First, it involves face-to-face communication between patients potentially possessing concrete information based on vivid experiences. Second, patient WOM originates from non-firm, non-marketing sources and is likely to be perceived as more credible than communications from marketers. Third, negative patient WOM can be extremely damaging because it is generally more widely communicated than positive WOM [5]. Thus, we employed WOM as a loyalty intention instrument in this study. A single item was measured using a 7-point Likert scale: "Will you recommend this hospital to someone who seeks your advice?" According to the recommendation of Bergkvist and Rossiter [45,46], "a carefully crafted single-item measure of a concrete construct is at least as valid as multiple-item measures of the same construct, and the use of a multiple-item measure then is not necessary" [46].

This study used a back translation procedure in two phases. During the first phase, the original questionnaire was translated from English into standard Mandarin Chinese by a Chinese English professor from Shanghai Foreigner Language School. In the second phase, a private translation company translated the Chinese questionnaire back into English. No differences were found between the two translations. This process has the advantage of pinpointing misinterpretations and misunderstandings before they reach the public [47]. Back translation therefore provides a test of content validity of our scales.

The questionnaire was administered in two different contexts identified as "Study 1" and "Study 2". Study 1 tested the questionnaire developed from the literature review and the constructs of reliability and validity. Study 2 used the constructs of Study 1 and tested each of the three models (Table 3).
Table 3 Descriptive statistics: means and standard deviations-Study 1

\begin{tabular}{|c|c|c|}
\hline \multirow{2}{*}{$\begin{array}{l}\text { Patient-perceived service quality items } \\
\text { Mean and standard deviation }\end{array}$} & \multicolumn{2}{|c|}{ Statistics } \\
\hline & M & SD \\
\hline 1 Prompt service to patients & 0.82 & 0.99 \\
\hline 2 Employees are consistently courteous & 0.61 & 0.86 \\
\hline 3 Employees deal with patients in a caring fashion & 0.64 & 0.84 \\
\hline 4 Providing services at the promised time & 0.65 & 0.88 \\
\hline 5 Employees understand the needs of patients & 0.79 & 0.99 \\
\hline $\begin{array}{l}6 \text { Visually appealing materials associated with the } \\
\text { service }\end{array}$ & 0.64 & 0.96 \\
\hline 7 Having the patient's best interest at heart & 0.93 & 1.00 \\
\hline 8 Willing to help patients & 0.69 & 0.98 \\
\hline 9 Maintaining error-free records & 0.55 & 0.76 \\
\hline $\begin{array}{l}10 \text { Keeping patients informed about when service will } \\
\text { be performed }\end{array}$ & 0.53 & 0.78 \\
\hline 11 Providing service as promised & 0.74 & 0.92 \\
\hline 12 Employees instill confidence in patients & 0.71 & 1.03 \\
\hline $\begin{array}{l}13 \text { Employees have the knowledge to answer patient } \\
\text { questions }\end{array}$ & 0.75 & 0.99 \\
\hline 14 Dependability in handing patients' requests & 0.66 & 0.89 \\
\hline 15 Readiness to respond to patients' requests & 0.77 & 1.06 \\
\hline 16 Performing services right the first time & 0.70 & 0.96 \\
\hline 17 Visually appealing living rooms \& environments & 0.95 & 1.08 \\
\hline 18 Giving patients individual attention & 0.91 & 1.07 \\
\hline 19 Employees have a neat, professional appearance & 0.43 & 0.74 \\
\hline 20 Convenient business hours & 0.77 & 0.98 \\
\hline 21 Modern living room facilities \& equipment & 0.89 & 1.00 \\
\hline 22 Making patients feel safe in their transactions & 0.68 & 0.91 \\
\hline \multicolumn{3}{|l|}{ Patient satisfaction items } \\
\hline $\begin{array}{l}\text { How would you rate the overall quality of service } \\
\text { provided by your hospital? (overall quality) }\end{array}$ & 7.36 & 1.30 \\
\hline $\begin{array}{l}\text { Thinking about this hospital overall, please rate the } \\
\text { value you feel you get for your money (value) }\end{array}$ & 7.10 & 1.38 \\
\hline Overall, how satisfied are you with this hospital? & 7.43 & 1.39 \\
\hline
\end{tabular}

(overall satisfaction)

\section{Loyalty intention item}

Recommend hospital to someone who seeks your

\section{Model estimation}

To assess the construct validity of the measures prior to model estimation, a three-step data analysis was undertaken $[48,49]$. First, a principal component analysis using a varimax rotation was performed to eliminate cross-loading items and to optimize scale validity and reliability. Second, the validity of each measurement was evaluated by conducting confirmatory factor analysis [50]. Third, convergent validity and discriminant validity were assessed for construct validity [51]. In this research, we 
used perceived quality and customer satisfaction influencing customer loyalty intention as a single item $[45,46]$.

The structural equations modeling (SEM) was used to estimate the relationships in our models. This technique was used to investigate patient satisfaction $[4,52]$. According to Iacobucci et al. [53], SEM performs better than regressions for mediation analysis. The software used was AMOS 5.0. Reflective measures indicators were used to build the different constructs of perceived quality, loyalty and satisfaction.

\section{Ethical considerations}

Ethical approval was obtained from the Research and Ethics Committee of the Centre of Hospital Management at the China Shanghai Fudan Medical University. Permission was also obtained from management at each of the hospitals participating in the study. Written consent to participate in the study was obtained from all study participants. The methodology used in this study followed the principles of the Helsinki Declaration.

\section{Results}

Study 1: measurement reliability and validity

Study 1 analyzed the reliability and validity of the measures. The questionnaire was based on the prior literature review. Using an iterative process, we removed items with non-significant loadings or loadings on multiple factors. By doing so, we ultimately revised the items and arrived at an instrument containing items that only directly assessed the construct presented in Table 4. This process left us with a shortened scale of five items loaded on one factor for the healthcare perceived quality concept. Three items were loaded on one factor for patient satisfaction. Confirmatory factor analysis results provided strong support for each related dimensional structure (Table 5).
The overall model fit of the measurement model was good. The chi-square value was 34.90 with 25 degrees of freedom; the p-value was less than 0.05. Model fit indices were also good according to $\mathrm{Hu}$ and Bentler [54], goodness of fit $(\mathrm{GFI})=0.949$, adjusted goodness of fit $(\mathrm{AGFI})=$ 0.909 , standardized root mean residual $($ SRMR $)=0.0350$ and root mean square error of approximation (RMSEA) = 0.05 . The average variance extracted [55] for the perceived quality construct was 0.672 , and the customer satisfaction construct was equal to 0.660 . In this study, the average variance extracted (AVE) was also used to evaluate discriminant validity between perceived quality and customer satisfaction constructs. According to Fornell and Larcker [55], if the AVE for each construct is greater than the squared correlation between the constructs, it confirms the discriminant validity. Examining the correlations between the perceived quality and customer satisfaction constructs, the correlation between these two constructs was 0.60 , and the squared correlation was 0.36 . Therefore, discriminant validity between these two constructs was checked, and the two constructs were distinct.

\section{Study 2: model test and comparison}

In this study, we used the scale from Study 1. Perceived service quality was measured using a 5-item scale, satisfaction was measured using a 3-item scale and loyalty intentions were measured by a single-item scale. Data collection was from the same sample of hospitals as in Study 1. Six hundred questionnaires were distributed at this stage for the second study, 480 surveys were completed before the deadline, giving an 80 percent response rate. Both exploratory and confirmatory factor analyses were performed to test the shortened subscale. The hypothesized relationships between perceived quality, customer satisfaction and customer loyalty intention constructs were tested via SEM.

Table 4 CFA model fit for each adapted dimensional structure

\begin{tabular}{|c|c|c|c|}
\hline Study 1 Instrument adaptation & Standardized loading & Variance extracted & Construct reliability \\
\hline Health care perceived quality (5 items) & & 0.722 & 0.903 \\
\hline Providing services at the promised time & 0.819 & & \\
\hline Providing service as promised & 0.846 & & \\
\hline Employees have the knowledge to answer patient questions & 0.875 & & \\
\hline Readiness to respond to patient requests & 0.860 & & \\
\hline Performing services right the first time & 0.849 & & \\
\hline Patient satisfaction (3 items) & & 0.852 & 0.913 \\
\hline $\begin{array}{l}\text { How would you rate the overall quality of service provided by } \\
\text { your hospital? }\end{array}$ & 0.932 & & \\
\hline $\begin{array}{l}\text { Thinking about this hospital overall, please rate the value you feel you } \\
\text { get for your money. }\end{array}$ & 0.905 & & \\
\hline Overall, how satisfied are you with your hospital? & 0.934 & & \\
\hline
\end{tabular}


Table 5 Confirmatory analysis of adapted dimensional structure CFA model fit)

\begin{tabular}{lcccccc}
\hline $\begin{array}{l}\text { Test of } \\
\text { constructs }\end{array}$ & Chi-Square (df) & GFI & AGFI & RMR & SRMR & RMSEA \\
\hline $\begin{array}{l}\text { Perceived } \\
\text { quality }\end{array}$ & $3.507(5)$ & 0.991 & 1.000 & 0.012 & 0.0141 & 0.000 \\
$\begin{array}{l}\text { Customer } \\
\text { satisfaction }\end{array}$ & $2.254(2)$ & 0.990 & 0.999 & 0.079 & 0.0095 & 0.029 \\
\hline
\end{tabular}

The overall model fit of the modified measurement model was still good. The chi-square value was 67.81 with 25 degrees of freedom, with $\mathrm{p}<0.05$, GFI $=0.970$, AGFI $=0.95$, SRMR $=0.0243$ and RMSEA $=0.06$. The AVE for the perceived quality construct was equal to 0.684 , and customer satisfaction was equal to 0.717 , which were greater than the squared correlation (0.399) between these two constructs. Thus, the discriminant validity of perceived quality and customer satisfaction constructs were confirmed.

After the evaluation of construct validity, these three research models of the relationship between perceived quality, patient satisfaction and patient loyalty intention constructs were tested simultaneously using SEM. The maximum likelihood method was used to investigate the covariance matrix of each item. The goodness of fit of the model was evaluated using absolute and relative indices. The value of GFI, RMSEA and SRMR were checked according to $\mathrm{Hu}$ and Bentler [54]. The model comparison was determined by calculating the difference in $X^{2}$ values [48]. The results of the model comparisons are reported in Table 6 .

\section{Test of the three models}

Model 1 tests the mediation role of customer satisfaction in the relationship between perceived quality and customer loyalty intention. Using Baron and Kenny's mediation model [26], two stages and four steps of data analysis were used during data interpretation. In stage 1 , the direct links between quality-satisfaction, satisfaction-loyalty and quality-loyalty were tested (Table 6). Stage 2 introduced these three constructs into a mediation model. As shown in Table 6, the regression coefficient indicated a strong and positive effect of patient perceived quality on patient satisfaction $(0.63, \mathrm{t}=13.38$, $\mathrm{p}<0.05)$. Patient satisfaction strongly and positively influenced patient loyalty intention $(0.48, \mathrm{t}=11.07, \mathrm{p}<$ 0.05). The standardized path coefficient indicated that patient-perceived quality statistically and positively influenced patient loyalty intention $(0.262, \mathrm{t}=2.95, \mathrm{p}<$ 0.05). Stage 2 tested the mediation role of customer satisfaction in the relationship between perceived quality and loyalty intention. The standard coefficients between patient perceived quality and patient loyalty intention were not statistically significant $(0.11, \mathrm{t}=1.16, \mathrm{p}=$

Table 6 Model results

\begin{tabular}{|c|c|c|c|c|c|c|c|c|c|c|c|}
\hline Model 1 Q-S-L & $x^{2}$ & df & $X^{2} / \mathrm{df}$ & $\mathbf{R}$ & $t$ & $R^{2}$ & TLI & GFI & AGFI & SRMR & RMSEA \\
\hline Stage 1:Q-S & 59.54 & 19 & 3.13 & 0.630 & $13.38^{*}$ & 0.398 & 0.977 & 0.970 & 0.943 & 0.0258 & 0.067 \\
\hline$S-L$ & 6.71 & 2 & 3.35 & 0.481 & $11.07^{*}$ & 0.231 & 0.995 & 0.993 & 0.965 & 0.0146 & 0.070 \\
\hline $\mathrm{Q}-\mathrm{L}$ & 14.21 & 9 & 1.57 & 0.262 & $2.95^{*}$ & 0.063 & 0.982 & 0.970 & 0.931 & 0.0339 & 0.060 \\
\hline Stage 2:Q-S-L & 34.90 & 25 & 1.40 & & & 0.366 & 0.980 & 0.949 & 0.909 & 0.0350 & 0.052 \\
\hline$S \leftarrow Q$ & & & & 0.605 & $6.998^{*}$ & & & & & & \\
\hline$L \leftarrow S$ & & & & 0.604 & $5.946^{*}$ & & & & & & \\
\hline $\mathrm{L} \leftarrow \mathrm{Q}$ & & & & 0.110 & 1.16 & & & & & & \\
\hline \multicolumn{12}{|l|}{ Model $2 \mathrm{Q}=\mathrm{S}$} \\
\hline & 89.03 & 26 & 3.42 & & & 0.317 & 0.906 & 0.895 & 0.817 & 0.2680 & 0.128 \\
\hline$L \leftarrow S$ & & & & 0.56 & $6.18^{*}$ & & & & & & \\
\hline$L \leftarrow Q$ & & & & 0.067 & 0.761 & & & & & & \\
\hline \multicolumn{12}{|l|}{ Model 3 S-Q-L } \\
\hline Stage $1: S-Q$ & 59.54 & 19 & 3.13 & 0.630 & $13.27^{*}$ & 0.398 & 0.977 & 0.970 & 0.943 & 0.0258 & 0.067 \\
\hline $\mathrm{Q}-\mathrm{L}$ & 14.21 & 9 & 1.57 & 0.262 & $2.95^{*}$ & 0.063 & 0.982 & 0.970 & 0.931 & 0.0339 & 0.060 \\
\hline$S-L$ & 6.71 & 2 & 3.35 & 0.481 & $11.07^{*}$ & 0.231 & 0.995 & 0.993 & 0.965 & 0.0146 & 0.070 \\
\hline Stage 2:S-Q-L & 34.90 & 25 & 1.40 & & & 0.366 & 0.980 & 0.949 & 0.909 & 0.0350 & 0.052 \\
\hline $\mathrm{Q} \leftarrow \mathrm{S}$ & & & & 0.605 & $6.998^{*}$ & & & & & & \\
\hline$L \leftarrow Q$ & & & & 0.110 & 1.16 & & & & & & \\
\hline$L \leftarrow S$ & & & & 0.604 & $5.946^{*}$ & & & & & & \\
\hline
\end{tabular}

$Q$, perceived quality; S, customer satisfaction; $L$, customer loyalty intention. * $\mathrm{p}<0.05$. 
0.245). This indicated that patient perceived quality and loyalty relationship depend on the level of patient satisfaction.

The overall model fit for model 1 was also acceptable, as indicated by the absolute fit and incremental fit indices (Table 6). The chi-square was 34.90 with 25 degrees of freedom, SRMR $=0.035, \mathrm{GFI}=0.949$ and $\mathrm{RMSEA}=$ 0.052. The model fit indices showed that the model fits the data. Data results indicated a complete mediation role of customer satisfaction in the relationship between perceived quality and loyalty intention for a service setting. Hypothesis 1 was thus supported.

Model 2 assumes that satisfaction and perceived quality influence loyalty intention equivalently, as these two constructs are considered as one and the same. Previous research has shown a clearly discriminant validity between these two constructs. This indicates that perceived quality and customer satisfaction are distinct. As shown in Table 3, the regression coefficient of perceived quality-loyalty intention and customer satisfaction-loyalty intention constructs were different. The regression coefficient of perceived quality on loyalty intention $(0.067, \mathrm{t}=$ $0.761, \mathrm{p}=0.45)$ and customer satisfaction on loyalty intention $(0.56, t=6.18, \mathrm{p}>0.05)$ were unequal, but both were statistically significant. This result confirms that perceived quality and customer satisfaction are statistically distinct constructs, and that they influence customer loyalty intention differently. Thus, Hypothesis 2 was rejected.

Model 3 tests the mediation role of perceived quality in the relationship between customer satisfaction and customer loyalty intention. As indicated in Table 3, the structural model for model 3 produced acceptable fit measures (chi-square 34.90 with 25 degrees of freedom; GFI $=0.949 ;$ SRMR $=0.035 ;$ RMSEA $=0.052$ ). Model 3 supported the same regression coefficient as model 1 for the perceived quality, satisfaction and loyalty intention constructs. It indicated the effect of perceived quality on satisfaction $(0.63, t=13.38, \mathrm{p}<0.05)$, satisfaction on loyalty intention $(0.48, \mathrm{t}=11.07, \mathrm{p}<0.05)$ and perceived quality on loyalty intention $(0.262, \mathrm{t}=2.95, \mathrm{p}<0.05)$.

However, contrary to model 1 , the role of perceived quality mediating the relationship between customer satisfaction and customer loyalty intention was not supported in model 3. The path coefficient of customer satisfaction to loyalty intention was not affected when perceived quality was introduced into the mediation model. Data results showed that the path coefficient of customer satisfaction to customer loyalty remained the same and continued at a statistically significant level (0.48, $\mathrm{t}=11.07, \mathrm{p}<0.05)$. Meanwhile, the perceived quality to customer loyalty construct reached a nonstatistically significant level $(0.11, \mathrm{t}=1.16, \mathrm{p}=0.245)$. In conclusion, these results strongly suggest that the mediation role of perceived quality is nonexistent in the relationship between customer satisfaction and loyalty intention, and model 3 was thus rejected.

\section{Discussion}

Because of strong competition in health services and changing consumer health attitudes, hospitals are now seeking to enhance patient loyalty using quality and satisfaction improvement strategies. If hospitals wish to be effective, it is critical that they clearly understand the relationship between these three concepts. In an effort to address this situation, this research empirically tested three theoretical models of perceived health service quality, patient satisfaction and patient loyalty relationship using a literature review as a basis for the studies. By integrating the mediation effect, this research also attempted to identify the role of mediation between these three constructs.

This study used hospital patients as participants. Empirical data came from a sample survey in six Chinese public hospitals. The investigated research models included three hypothesized relationships of these three constructs: 1) patient satisfaction mediates perceived quality and patient loyalty intention; 2) perceived quality and patient satisfaction have an equivalent impact on patient loyalty; and 3) perceived quality mediates patient satisfaction and patient loyalty intention. Construct reliability and validity were demonstrated by exploratory and confirmatory factor analysis for each construct. Relationships between each concept were analyzed using SEM.

\section{Model comparison}

Our results confirm that in a health service encounter, perceived quality and patient satisfaction are distinct, and both constructs lead to patient loyalty intention. Through the path coefficient, a high and positive correlation between perceived quality and patient satisfaction was found. The correlation between quality-loyalty and satisfaction-loyalty were both positive, but weaker than the quality-satisfaction relationship.

Proposed theoretical model 1, with patient satisfaction as a mediator between healthcare perceived quality and patient loyalty, provides an acceptable fit for the model evaluation. It confirms that perceived quality and patient satisfaction both lead to patient loyalty intention, and that the relationship between quality and loyalty is largely influenced by patient satisfaction, because satisfaction acts as a mediator between quality-loyalty relationships. In this approach, the first model "patient satisfaction mediates the relationship between perceived quality and patient loyalty" was supported in our research. 
Proposed theoretical model 2, with perceived quality and patient satisfaction both influencing patient loyalty equally, was not supported in this study. According to the model evaluation, the chi-square value was 89.03 with 26 degrees of freedom. This indicated that the model did not fit the data. Moreover, the path coefficients of quality-loyalty and satisfaction-loyalty were not equivalent. Thus, the second model was rejected.

Proposed theoretical model 3, with perceived quality as a mediator between the patient satisfaction and patient loyalty intention relationship, was not supported in this study. The path coefficient indicated that patient satisfaction impacts patient loyalty directly, and that perceived quality is not a mediator of the relationship between patient satisfaction and loyalty intention. Thus, model 3 was rejected.

\section{Limitations}

Our study suffers from several limitations and we address these in combination with suggestions for future research avenues.

First, this study uses hospital inpatients as research participants. Compared with inpatients that generally spend a lot of time in one particular department, outpatients may have brief experiences with several departments, and thus be able to provide an overall evaluation of the service quality of that hospital. Therefore, the key dimensions of perceived quality may differ between inpatients and outpatients in a single hospital. According to Cho et al. [5], the single-site sample used in this study may represent a limitation to the generalizability of the findings.

Second, past studies on patient satisfaction have been geographically concentrated in the United States and Western Europe, with only a limited number addressing Asian countries (e.g., Korea, India and Malaysia). Few studies have focused on the mainland Chinese market (there have been previous studies on Hong Kong and Taiwan); thus, the findings of this study provide insight into the quality-satisfaction and loyalty relationship in the mainland Chinese market. The dimensionality and item content of perceived quality are different than those studies targeting U.S., European or Asian subjects. Thus, future studies could be conducted to compare the content validity of perceived quality instruments and cultural differences between healthcare consumers.

Third, the results presented here are based on analysis of a causal model with cross-sectional data. Research results support a priori causal effects. However, longterm effects cannot be inferred. Addressing this limitation represents an extensive exercise via longitudinal studies, and would be fruitful for future research.

Fourth, this study uses single-item measures of customer loyalty. Although recent results regarding the predictive validity of single items are good [45], the justification for their use in scientific marketing research continues to be debated [56-59].

Fifth, as expectations and perceived quality were measured at the same time, study results might suffer from a response shift problem [60]. A response shift problem might have occurred because adjustments could have occurred between expectations and perceived quality experiences.

Sixth, this research used SEM to compare the relationship between patient-perceived quality, patient satisfaction and loyalty intention using three models. For explanatory purposes, we did not focus on socio-demographic differences. This could also be a new direction for future research.

\section{Conclusion}

This article supports the literature of Bitner [15]; Bolton and Drew [16]; Parasuraman, Zeithaml, and Berry [18,19]; Oliver [20]; Rust and Oliver [21]; and Zeithaml, Berry, and Parasuraman [22]. It emphasizes the distinction between perceived quality and customer satisfaction, with perceived quality as an antecedent of customer satisfaction in a service setting. From the empirical data, we confirm a mediation role of patient satisfaction in the relationship between perceived quality and patient loyalty. This result offers important implications for both marketing researchers and healthcare managers.

This study used the perceived service quality standard scale (SERVQUAL), adapted to suit health services. This scale was selected because of its widespread use. However, it focuses more on services provided than on the full spectrum of the patient experience [27]. Our adaptation of the SERVQUAL instrument using a singledimensional measure confirms Babakus and Mangold's [27] findings. Therefore, our results indicate that the adapted SERVQUAL scales can be used to assess service quality in the Chinese healthcare sector.

Other studies, however, have conceptualized service quality constructs using different numbers of dimensions. For instance, in the healthcare sector, Cho et al. [5] confirmed a four-dimensional structure of perceived health service quality in South Korea. Anbori et al. [61] identified a six-dimensional structure of perceived health service quality in Yemen. The nature of the concept of perceived health service quality is at the origin of this difference. In this paper, we use a reflective measure of the concept because we are interested in comparing models. For explanatory purposes, researchers might prefer formative models using causal links. The patientreported experience concept [62] is formative by nature because it takes into account the various causes of perceived health service quality (e.g., doctor and nursing services, information examinations, organization, hospital 
and equipment). Such a focus is therefore multidimensional, and the indicators do not need to have strong covariations [63].

\section{Competing interests}

The authors declare that they have no competing interests.

\section{Authors' contributions}

JA designed the study. PL conducted the data collection. PL and JA analyzed the data. PL drafted the manuscript. JA and PL contributed to interpretation of findings and revision of the manuscript. JA supervised the study. All authors have read and approved the final manuscript.

\section{Acknowledgments}

The study is the PhD dissertation work of Ping Lei at the CERAG/CNRS, University Pierre Mendes France (Grenoble University France). The authors are indebted to FUDAN Shanghai (College of Public Health) for mailing our questionnaires to six of their university hospitals, and to Shanghai FUDAN Hospital/Healthcare Management Company for the data collection and patient recruitment. The authors thank all the participants who were involved in the study.

\section{Author details}

${ }^{1}$ Groupe Ecole Supérieure de Commerce Chambéry Savoie, France, 12 Avenue du Lac d'Annecy, Le Bourget du Lac Cedex, Chambéry, Savoie 73381, France. ${ }^{2}$ Centre d'études et de Recherches Appliquées à la Gestion de Université Pierre Mendes France, Grenoble 2, France.

Received: 5 January 2012 Accepted: 27 November 2012

Published: 30 November 2012

\section{References}

1. Hew C: Healthcare in china toward greater access, efficiency and quality. New York: IBM Business Consulting; 2006. http://www-935.ibm.com/services/us/ imc/pdf/g510-6268-healthcare-china.pdf

2. Deitrick LM, Capuano TA, Paxton SS, Stern G, Dunleavy J, Miller WL: Becoming a leader in patient satisfaction: changing the culture of care in an academic community hospital. Health Mark Q 2006, 23(3):31-57.

3. Sitzia J, Wood N: Patient satisfaction: a review of issues and concepts. Soc Sci Med 1997, 45(12):1829-1843.

4. Carlin CS, Christianson JB, Keenan P, Finch M: Chronic illness and patient satisfaction. Health Serv Res 2012, 47(4):1-23.

5. Yoo S: Service quality at hospitals. Asia Pacific Adv Consum Res 2005, 6:188-193.

6. Cronin JJ, Taylor SA: SERVPERF Versus SERVQUAL: reconciling performance-based and perceptions-minus-expectations measurement of service quality. J Marketing 1994, 58(1):125-131.

7. McAlexander $\mathrm{JH}$, Kaldenberg DO, Koenig HF: Service quality measurement. J Health Care Mark 1994, 14(3):34-39.

8. Cho WH, Lee H, Kim C, Lee S, Choi HS: The impact of visit frequency on the relationship between service quality and outpatient satisfaction: a South Korean study. Health Serv Res 2004, 39(1):13-33.

9. Wu HL, Liu CY, Hsu WH: An integrative model of customer's perceptions of health care services in Taiwan. Ser Ind J 2008, 28(9):1307-1319.

10. Lam SSK: SERVQUAL: a tool for measuring patients' opinions of hospital service quality in Hong Kong. Total Qual Manage 1997, 8(4):145-152.

11. Hennig-Thurau T, Kee A: The impact of customer satisfaction and relationship quality on customer retention: a critical reassessment and model development. Psychol Market 1997, 14(8):737-764.

12. Ball D, Coelho PS, Vilares MJ: Services personalization and loyalty. J Serv Mark 2006, 20(6):391-403

13. Chou SM, Chen TF, Woodard B, Yen MF: Using SERVQUAL to evaluate disconfirmation of nursing service in Taiwan. J Nurs Res 2005, 13(2):75-83.

14. Boshoff C, Gray B: The relationship between service quality, customer satisfaction and buying intentions in the private hospital industry. S Afr J Bus Manag 2004, 35(4):27-35.

15. Bitner MJ: Evaluating service encounters: the effect of physical surroundings and employee responses. J Marketing 1990, 54(2):69-82.

16. Bolton RN, Drew JH: A multistage model of customer's assessments of service quality and value. J Consum Res 1991, 17(4):375-384.
17. Bolton RN, Drew JH: Linking customer satisfaction to service operations and outcomes. In Service quality: New directions in theory and practice. Edited by Rust RT, Oliver RL. Thousand Oaks, California: Sage; 1994:173-200

18. Parasuraman A, Zeithaml VA, Berry L: SERVQUAL: a multiple-item scale for measuring consumer perceptions of service quality. J Retailing 1988 67(1):12-40.

19. Parasuraman A, Zeithaml VA, Berry L: Reassessment of expectations as a comparison standard in measuring service quality: implications for further research. J Marketing 1994, 58(1):111-124.

20. Oliver RL: A conceptual model of service quality and service satisfaction: compatible goals, different concepts. Ad Serv Mark Man 1993, 2:68-85.

21. Rust RT, Oliver RL: Service quality insights and managerial implications from the frontier. In Service quality: New directions in theory and practice. Edited by Rust RT, Oliver RL. Thousand Oaks, California: Sage Publications; 1994:1-19.

22. Zeithaml VA, Berry L, Parasuraman A: The nature and determinants of customer expectations of service. J Acad Market Sci 1993, 21(1):1-12.

23. Oliver RL: A cognitive model of the antecedents and consequences of satisfaction decisions. J Marketing Res 1980, 17(4):460-469.

24. Oliver RL: Satisfaction: A behavior perspective on the consumer. New York: McGraw-Hill; 1997.

25. Johnson MD, Anders G, Tor WA, Line L, Jaesung C: The evolution and future of national customer satisfaction index models. J Econ Psychol 2001, 22(2):217-245.

26. Baron RM, Kenny DA: The moderator-mediator variable distinction in social psychological research: conceptual, strategic and statistical considerations. J Pers Soc Psychol 1986, 51(6):1173-1182.

27. Babakus E, Mangold WG: Adapting SERVQUAL scale to hospital services: an empirical investigation. Health Serv Res 1992, 26(1):767-786.

28. Donabedian A: The effectiveness of quality assurance. Int I Qual health $C$ 1996, 18(4):401-407.

29. lacobucci D, Amy O, Kent G: Distinguishing service quality and customer satisfaction: the voice of the consumer. J Consum Psychol 1995, 4(3):277-303.

30. Sternthal B, Tybout AM, Calder BJ: Confirmatory versus comparative approaches to judging theory tests. J Cons Res 1987, 14(1):114-125.

31. Duffy JA, Duffy M, Kilbourne W: A comparative study of resident, family and administrator expectations for service quality in nursing homes. Health Care Manage R 2001, 26(3):75-85.

32. Lynn MR, McMillen BJ: Do nurses know what patients think is important in nursing care? J Nurs Care Qual 1999, 13(5):65-74.

33. Oliva TA, Oliver RL, MacMillan IC: A catastrophe model for developing service satisfaction strategies. J Marketing 1992, 56(3):83-95.

34. Dabholkar PA: Customer satisfaction and service quality: two constructs or one? In Enhancing knowledge development in marketing. Edited by Cravens DW, Dickson P. Chicago: American Marketing Association; 1993:10-18. ISBN 4

35. Li XM, Huang JS, Zhang H: An analysis of hospital preparedness capacity for public health emergency in four regions of China: Beijing, Shandong, Guangxi, and Hainan. BMC Publ Health 2008, 8:319.

36. USA Social Security Administration: Age of receive full social security retirement benefits. Baltimore:; 2011. http://www.socialsecurity.gov

37. Parasuraman A, Zeithaml VA, Berry L: A conceptual model of service quality and its implications for future research. J Marketing 1985, 49(3):41-50.

38. Fitzpatrick R: Capturing what matters to patients when they evaluate their hospital care. Qual Saf Health Care 2002, 11(4):306-306.

39. Prakash $\mathrm{V}$ : Validity and reliability of the conformation of expectations paradigm as a determinant of consumer satisfaction. J Acad Market Sci 1984, 12(4):063-076.40.

40. Coelho PS, Esteves SP: The choice between a five-point and a ten-point scale in the framework of customer satisfaction measurement. Int J Market Res 2007, 49(3):313-339.

41. Garratt AM, Helgeland J, Gulbrandsen PJ: Five-point scales outperform 10-point scales in a randomized comparison of item scaling for the patient experiences questionnaire. J Clin Epidemiol 2011, 64(2):200-207

42. Baumgartner $\mathrm{H}$, Steenkamp JEM: Response styles in marketing research: a cross-national investigation. J Marketing Res 2001, 38(2):143-156.

43. Churchill JR, Gilbert A, Peter JP: Research design effects on the reliability of rating scales: a meta-analysis. J Marketing Res 1984, 21(4):360-375. 
44. Ferguson RJ, Paulin M, Leiriao E: Loyalty and positive word-of-mouth: patients and hospital personnel as advocates of a customer-centric health care organization. Health Mark Q 2006, 23(3):59-77.

45. Bergkvist $L$, Rossiter JR: The predictive validity of multiple-item vs. singleitem measures of the same constructs. J Marketing Res 2007, 44(2):175-184

46. Bergkvist L, Rossiter JR: Tailor-made single-item measures of doubly concrete constructs. Int J Advert 2009, 28(4):607-621.

47. Craig CS, Douglas SP: International marketing research. Chichester: JohnWiley and Sons; 2005

48. Anderson JC, Gerbing DW: Structural equation modeling in practice: a review and recommended two-step approach. Psychol Bull 1988, 103(3):411-423.

49. Bagozzi RP, Yi Y: On the evaluation of structural equation models. J Acad Market Sci 1988, 16(1):74-94.

50. Arbuckle JL: Amos 5.0. Update to the Amos User's guide. Chicago, Illinois: SmallWaters Corporation; 2003.

51. Baumgartner $\mathrm{H}$, Homburg $\mathrm{C}$ : Applications of structural equation modeling in marketing and consumer research: a review. Int J Res Mark 1996, 13(2):139-61.

52. Sahin B, Yilmaz F, Lee $\mathrm{KH}$ : Factors affecting inpatient satisfaction: structural equation modeling. J Med Syst 2007, 31(1):9-16.

53. lacobucci D, Saldanha N, Deng XY: A meditation on mediation: evidence that structural equations models perform better than regressions. J Consum Res 2007, 17(2):139-153.

54. Hu LT, Bentler PM: Cutoff criteria for fit indexes in covariance structure analysis: conventional criteria versus new alternatives. Struct Equ Modeling 1999, 6(1):1-55.

55. Fornell C, Larcker DF: Evaluating structural equation models with unobservable variables and measurement error. J Marketing Res 1981, 48(1):39-50

56. Rossiter JR: The C-OAR-SE procedure for scale development in marketing. Int J Res Mark 2002, 19(4):305-335.

57. Diamantopoulos A: The C-OAR-SE procedure for scale development in marketing: a comment. Int J Res Mark 2005, 22(1):1-9.

58. Doorn JV, Verhoef PC: Critical incidents and the impact of satisfaction on customer share. J Marketing 2008, 72(4):123-142.

59. Donabedian A: The quality of care: how can it be assessed? J Am Med Assoc 1988, 260(12):1743-1748.

60. Schwartz CE, Sprangers MA: Methodological approaches for assessing response shift in longitudinal health-related quality-of-life research. Soc Sci Med 1999, 48(11):1531-1548.

61. Anbori AK, Ghani SN, Yadav H, Daher AM, Su TT: Patient satisfaction and loyalty to the private hospitals in Sana'a, Yemen. Int J Qual Health C 2010, 22(4):310-315

62. Bjertnaes OA, Sjetne IS, Iversen HH: Overall patient satisfaction with hospitals: effects of patient-reported experiences and fulfillment of expectations. BMJ Oual Saf 2012, 21(1):39-46.

63. Jarvis CB, Mackenzie SB, Podsakoff PM: A critical review of construct indicators and measurement model misspecification in marketing and consumer research. J Consum Res 2003, 30(2):199-218.

doi:10.1186/1472-6963-12-436

Cite this article as: Lei and Jolibert: A three-model comparison of the relationship between quality, satisfaction and loyalty: an empirical study of the Chinese healthcare system. BMC Health Services Research 2012 $12: 436$

\section{Submit your next manuscript to BioMed Central and take full advantage of:}

- Convenient online submission

- Thorough peer review

- No space constraints or color figure charges

- Immediate publication on acceptance

- Inclusion in PubMed, CAS, Scopus and Google Scholar

- Research which is freely available for redistribution 